\title{
Allocation of pharmaceutical resources in maternal and child healthcare institutions during the COVID-19 pandemic
}

\author{
(D) jianghui Cai ${ }^{1}$ \\ iD Wenwen Chen $\mathbf{1 , 2}$ \\ Xiao Yang ${ }^{1}$ \\ (D) Xiuqing Yang ${ }^{1}$ \\ (iD) Gen Li ${ }^{1}$
}

1. Department of Pharmacy, Chengdu Women's and Children's Central Hospital, School of Medicine, University of Electronic Science and Technology of China, Chengdu 610041, China;

2.School of Pharmacy, Chengdu University of Traditional Chinese Medicine, Chengdu 611137, China

http://dx.doi.org/10.1590/1806-9282.66.S2.41

\section{SUMMARY}

Since the outbreak of a cluster of patients with pneumonia of unknown cause in Wuhan, Hubei Province, China, in December 2019 , the disease was later officially named coronavirus disease 2019 (COVID-19) caused by the novel severe acute respiratory syndrome coronavirus (SARS-CoV-2), quickly spreading globally. Pregnant women and children are particularly vulnerable during disasters and emergencies. Comprehensive and applicable emergency preparedness and response are definitely important methods to prevent and contain the COVID-19 pandemic. The rational allocation of pharmaceutical resources plays an important role in the medical emergency plan. This paper aimed to share experiences for the allocation of pharmaceutical resources in hospitals focusing primarily on women and children during the COVID-19 pandemic.

KEYWORDS: Coronavirus Infections. Pregnancy. Child. Pharmaceutical Services.

\section{INTRODUCTION}

Since the outbreak of pneumonia of unknown cause in Wuhan, China in December 2019, the disease was later named Coronavirus disease 2019 (COVID-19) caused by the novel severe acute respiratory syndrome coronavirus (SARS-CoV-2) and quickly spreading throughout China and other countries' ${ }^{1}$. The World Health Organization (WHO) declared the sixth public health emergency of international concern over the global outbreak of COVID-19 on January 30, 2020. To date, COVID-19 has affected more than 180 countries or regions with 5,204,508 confirmed and 337,687 deaths, and $\mathrm{WHO}^{2}$ has warned countries that the crisis is generating stress worldwide. On March 11, 2020, the WHO declared the COVID-19 outbreak a global pandemic. The COVID-19 pandemic has put enormous pressure on public health systems around the world and highlights the importance of emergency preparedness and response (EP\&R). The rational allocation of pharmaceutical resources plays an important role in public health to prevent and stop the

DATE OF SUBMISSION: 21-Jun-2020

DATE OF ACCEPTANCE: 11-Jul-2020

CORRESPONDING AUTHOR: Gen Li

Department of Pharmacy, Chengdu Women's and Children's Central Hospital, School of Medicine, University of Electronic Science and

Technology of China, Chengdu city 610041, China

E-mail:393155450@qq.com 
spread of the COVID-19 pandemic. Pregnant women and children are generally susceptible to COVID-19 considering they are in a special state of immune suppression ${ }^{3}$. Pregnant women might be more prone to have more rapid clinical deterioration due to COVID19 because of decreased lung volumes caused by the increase in uterus size during pregnancy. As for children, the youngest patient received confirmation of the COVID-19 infection just 2 hours after birth ${ }^{4}$. According to a study from China, it appears that children have a lower prevalence, only $1 \%$ of confirmed cases were aged 9 years or younger, $1 \%$ of confirmed cases were aged 10 to 19 years. Most confirmed cases were classified as mild (i.e., non-pneumonia and mild pneumonia) $)^{5}$. Unfortunately, there have already been death reports in children ${ }^{6}$. Despite a lack of data on the consequences of COVID-19 infections during pregnancy, coronaviruses are responsible for severe acute respiratory syndrome (SARS-CoV) and Middle East respiratory syndrome (MERS-CoV), and have the potential to cause severe adverse outcomes during pregnancy ${ }^{7-9}$. Asymptomatic infections were common in pregnant women and children ${ }^{10,11}$. Thus, the continued vigilance of women and children affected by COVID-19 is warranted.

An effective medical emergency plan is important to respond to the COVID-19 pandemic, and the rational allocation of pharmaceutical resources is an indispensable part of an effective medical emergency plan. Until now, all of the medical emergency plans are for general hospitals, but no articles were found specific to maternal and child health care institutions ${ }^{12-15}$. To the best of our knowledge, this is the first article on the allocation of pharmaceutical resources in maternal and child healthcare institutions when a public health emergency happens. Our hospital is the designated site for women and children with suspected COVID-19 in Chengdu city. On February 20, 2020, an international team of experts led by the WHO visited our hospital to learn about measures and recommendations for the management of pregnant women and children during the COVID-19 pandemic.

This article aimed to share experiences for the rational allocation of pharmaceutical resources in hospitals focusing primarily on women and children during the COVID-19 pandemic to protect their safety faster and better.

Here, we propose seven recommendations for the allocation of pharmaceutical resources in maternal and child healthcare institutions during the COVID-19 epidemic. Each of these components is discussed in more detail below (Figure1).

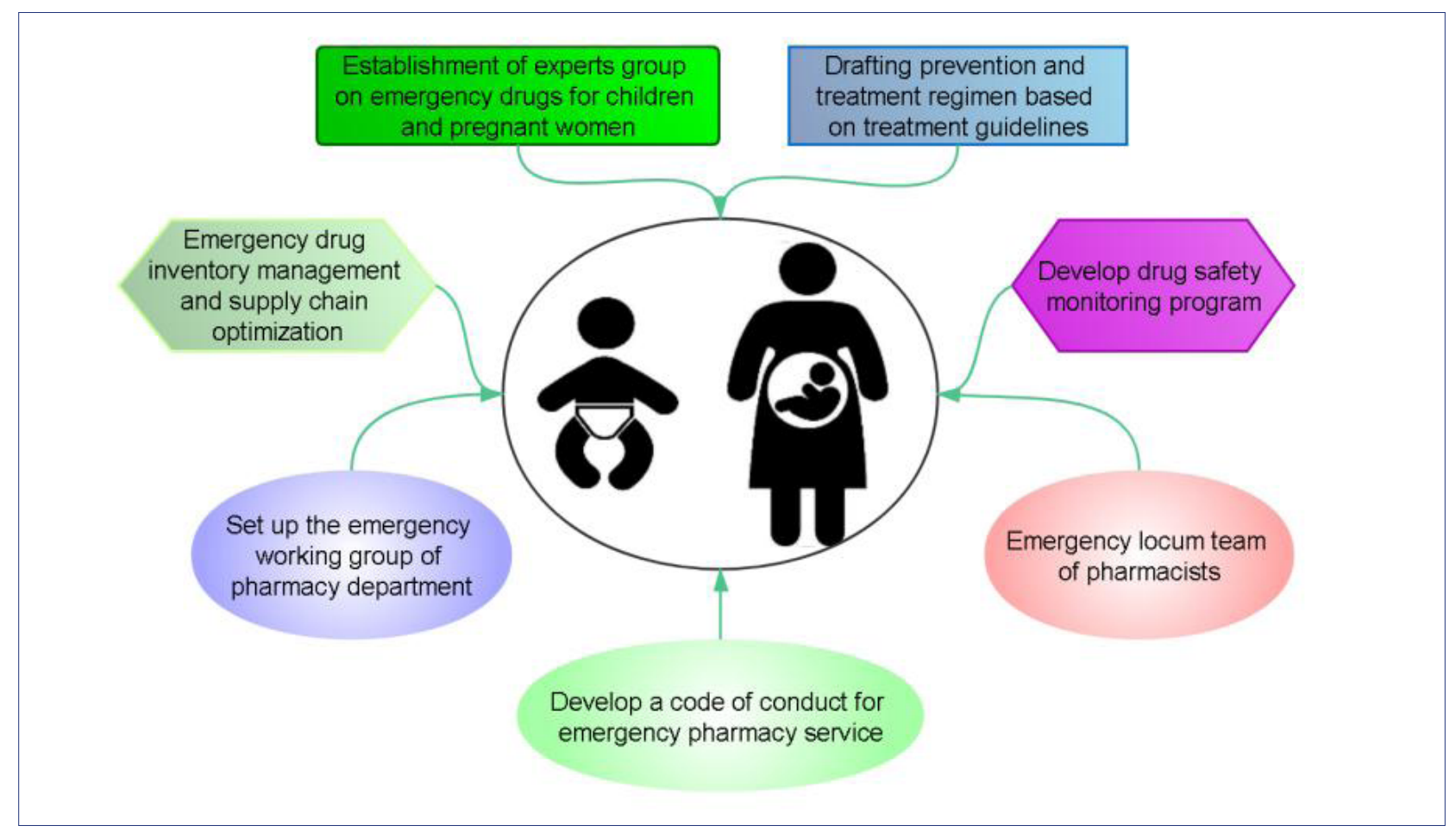

FIGURE 1. THE COMPONENTS FOR THE ALLOCATION OF PHARMACEUTICAL RESOURCES IN MATERNAL AND CHILD HEALTHCARE INSTITUTIONS IN THE COVID-19 PANDEMIC 
1. Establishment of a group of experts on emergency drugs for children and pregnant women

Special attention should be given to pregnant women and children during the COVID-19 pandemic. It is well known that the pharmacokinetic characteristics, safety, and efficacy of medication during pregnancy were significantly different from that of the general population. At the same time, most drugs and their metabolites can cross the placenta and have some effect on human fetuses ${ }^{16}$. The effects of drugs on both mother and fetus should be taken into consideration, assessing the benefit-risk ratio, and drugs should only be used if the benefits to the mother outweigh the potential risks to the fetus. Furthermore, the effects of drugs on the fetus are not the same at different stages of pregnancy. In general, the first trimester of pregnancy is most susceptible to drugs, especially during the teratogenically sensitive period. It is noteworthy that children are not miniature adults when it comes to rational drug use, but a special medication group. Because their organs are under development, glomerular filtration rate, tubular secretory capacity, and liver drug-metabolizing enzyme are known to be immature, thus the response to drugs is also different from adults. Children have important physiological and developmental needs that are distinct from adults, and in the event of an emergency situation, they need specialized care involving personalized medicine. Simply placing children under medication as a smaller version of the adult drug use may cause more harm than good to children. Thus, it is urgent to establish a multidisciplinary expert group on emergency drugs for children and pregnant women in the first place. Experts should include: clinical pharmacists, pediatricians, obstetricians, respiratory physicians, infectious disease physicians, and medical staff from the hospital infection control departments.

\section{Drafting prevention and treatment regimen based on treatment guidelines}

There is an urgent need for an effective treatment for COVID-19. However, until now, there is no vaccine or proven effective specific antiviral drug treatment for COVID-19. The "Diagnosis and Treatment Guidelines for the New Coronavirus Infected Pneumonia ( $7^{\text {th }}$ edition)" was released by the China National Health Commission focusing primarily on adults ${ }^{17}$. An expert group drafted a prevention and treatment regimen for pregnant women and children based on the treatment guidelines. Some drugs should not be considered because of the teratogenic effect on the fetus, such as ribavirin. In parallel, the dosage should be determined according to the patient's weight, age, and body surface area. Considering most drugs recommended in the guidelines are of off-label use, pharmacists should assist physicians in in evaluating the efficacy and safety of these drugs and inform patients of potential adverse drug reactions (ADR).

\section{Emergency drug inventory management} and supply chain optimization

Healthcare organizations need inventory and shortage management strategies to address the rapidly escalating demand for medications due to the COVID19 pandemic. Emergency drug inventory should include not only drugs for the direct treatment of the disease but also drugs for supportive care because the current management of COVID-19 consists mostly of symptomatic supportive treatment ${ }^{18}$. The clinical characteristics of the COVID-19 infection during pregnancy are similar to those observed in non-pregnant adult patients confirmed with COVID-19 ${ }^{11}$, and children appear to have a milder clinical course ${ }^{19}$. Common signs and symptoms including fever and cough in pregnant women and children indicate there is an increasing demand for antipyretics and antitussives, such as Paracetamol and dextromethorphan ${ }^{11,19}$. Other drugs such as chloroquine, hydroxychloroquine, azithromycin, and antivirals can also be in short supply. Drugstores in China ran out of their antipyretics stock within days of the first COVID-19 case being identified. To curb the hoarding of antipyretics and antitussives, China adopted unprecedented nationwide measures such as requiring an identification card for the purchase of antipyretics drugs during the early phase of the COVID-19 pandemic. The time of the COVID-19 outbreak in Wuhan coincided with the Chinese New Year Festival, with a 7-day long holiday for working professionals. Some manufacturers had difficulties to resume production due to short raw materials stocks. Transportation and logistics in all cities were limited in China, which delayed the transporting time domestically. Having foreseen that emergency situations can disrupt access to medications, our hospital established an emergency drug inventory in the initial days since the closedown of Wuhan on January 23, 2020. As mentioned previously, hospitals must plan to rely on their own assets for at least 7 days. We began filling a 2-week emergency drug supply in anticipation of the 
COVID-19 pandemic possibly disrupting our normal filling schedule. Pharmacists could play an important role in estimating supplies during emergencies and ensure adequate stocks of medications for chronic illnesses, anti-infectives, and commonly used OverThe-Counter (OTC) products are available. At the same time, pharmacists should establish surveillance and warning mechanisms to address drug shortages in a timely manner. An essential assessment to calculate the current supply and when it will be used up should be done daily.

Challenges in procurement are likely to result from disruptions to supply chains. Thus it is essential to track the drug inventory level and coordinate with major manufacturers to ensure an uninterrupted supply chain and accurately forecast inventories for existing medications and supplies. Uninterrupted drug supply of critical medications should be ensured and collaborations established with other maternal and child healthcare institutions to procure essential medications and supplies. Clinical pharmacists should give advice on therapeutic exchanges and substitutions and optimize medications based on evidence-based medicine if drug shortages happen.

\section{Develop a drug safety monitoring program}

Clinical pharmacists collaborate with physicians to monitor the use of drugs in pregnant women and children in various ways. Such as providing information on the dosage, known risks, and drug interactions to patients or their family members using booklets or through medication education. Obtain up-to-date information of patients from the electronic medical record system, patients with complications such as renal and hepatic impairment are the primary focus because they are more prone to adverse drug reactions; if adverse drug reactions happen, medication use should be withdrawn or switched to evidence-based treatment alternatives. Therapeutic Drug Monitoring (TDM) can be used to monitor the use of critical care drugs and selected anti-infectives, optimize medication usage, and reduce the side effects. Other drug safety monitoring measures include providing stewardship on antimicrobial resistance to addressing the abuse of antibiotics, individualizing medication instructions that help improving medication adherence, interpreting and discussing with patients when there are no available alternatives, offering comprehensive medical services to pregnant women and children including evaluating potential drug safety events and monitoring health outcomes to limiting inappropriate use of drugs.

\section{Set up an emergency working group with} the pharmacy department

In order to ensure the normal operation of the pharmacy department, it is necessary to set up an emergency working group. The members of the emergency working group should include the director of the pharmacy, manager of the drug depot, manager of the outpatient and inpatient pharmacy, manager of the emergency pharmacy, pharmacovigilance director, and division director of clinical pharmacy. Pharmacy services have always been considered essential services during an emergency. Emergency working groups need to take a series of measures aimed at minimizing disruptions in pharmacy services during the COVID-19 pandemic. Each member has a different role and performs their duties to provide critical access to medications (Figure 2). The manager of the drug depot must be responsible for formulating the drug purchase plan according to the treatment guidelines

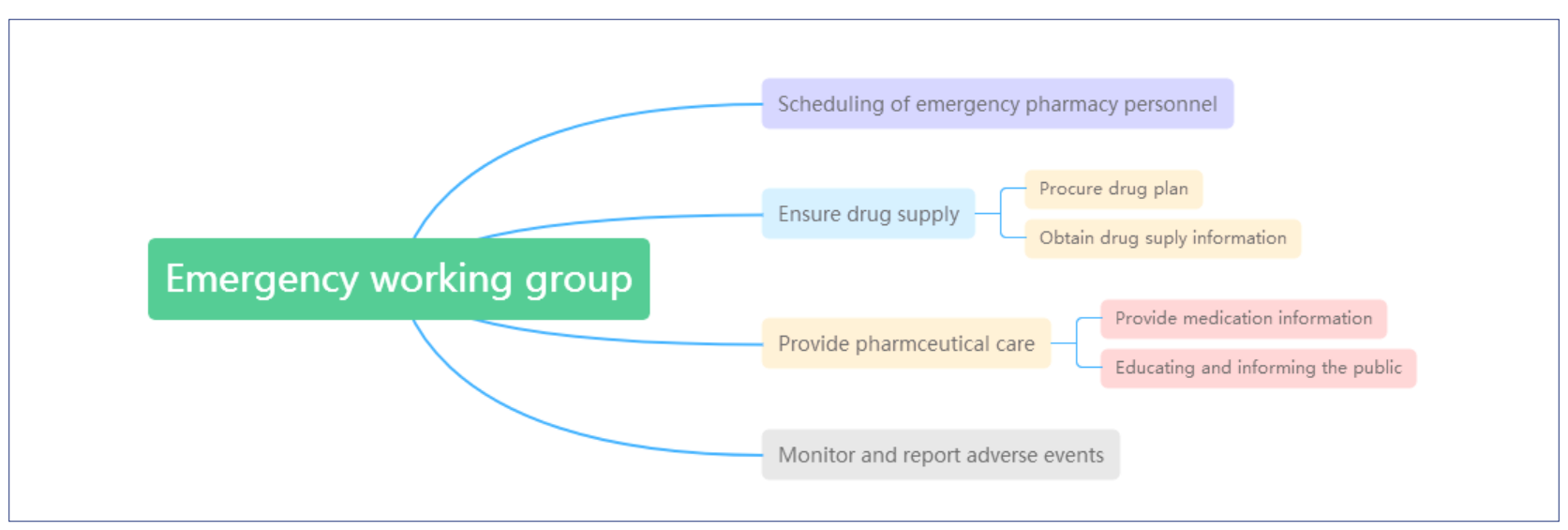

FIGURE 2. THE ROLES AND DUTIES OF THE EMERGENCY WORKING GROUP DURING THE COVID-19 PANDEMIC 
or expert group opinions formulated by the hospital, obtaining drug supply information from multiple channels, considering the mutual substitution of drugs, grasping the allocation channel, supply, and allocation information of the hospital's emergency rescue drugs, and ensuring the rapid purchase and transportation to facilitate medication refills. Special personnel should be assigned to be responsible for the management of emergency drugs, and ensure that medications are effectively received, stored, and dispensed properly. The manager of the outpatient and inpatient pharmacy must be responsible for the organization and scheduling of emergency pharmaceutical personnel. A special pharmacy needs to be set up for infectious diseases and disinfection should be done. They should provide medication information for the clinic, ensure drug supply, educate, and inform the public. The pharmacovigilance director should monitor and report adverse events, highly focused on adverse drug reactions, overdoses, misuse, abuse of drugs, and drug exposure during pregnancy and breastfeeding. The members of the emergency working group should keep mobile phones on 24 hours to ensure that emergency services can be launched timely.

\section{Emergency locum team of pharmacists}

There is no doubt that pharmacists around the world have significant roles to play and contribute to the overall emergency management, especially during pandemics like that of the COVID-19. Community and hospital pharmacies are improving public health by expanding services and hours to provide essential services, putting pharmacists and their colleagues at the frontlines for patient care and safety ${ }^{20}$. Pharmacy professionals have been highly responsive to the crisis in China since the outbreak, either at hospitals and community pharmacies or at the square cabin hospitals in Wuhan ${ }^{21}$. Pharmacists are one of the most accessible healthcare professionals with the potential to provide pharmaceutical care and health information. As one of the frontline healthcare professionals, pharmacists focused on continuing to provide pharmacy services to patients while they were at high risk for COVID-19 infection, and adequate equipment and supplies should be available for physicians, nurses, and pharmacy staff, including students, interns, and part-time workers to protect them from infections with SARS-CoV-2. Extending working hours and the heavy workload for dealing with supply shortages and resource allocations made pharmacists exhausted, stressed, and fatigued. One of the early reported deaths of healthcare workers during the COVID-19 pandemic involved a 28-yearold pharmacist, Dr. Song Yingjie, who died of sudden cardiac death after working for ten days straight ${ }^{22}$. Since the first day of the lunar New Year, Dr. Song Yingjie had been on duty and was responsible for the distribution of medical supplies in the warehouse of the hospital. He died at the end of the midnight shift after he returned to the dormitory on February 3 . In response to emergencies, we set up an emergency locum team and hired pharmacy interns for emergency personnel augmentation. The emergency locum team consists of six pharmacists with more than 3 years of work experience and arranged according to three shifts daily. Meanwhile, another six pharmacists in the second tier must be reserved to cope with the abnormal reduction of staff. If any pharmacy staff become sick, sick leaves are granted not only for them to rest and recover, but also to avoid infecting patients and coworkers. All staff must be rotated for 14 days to reduce the pressure on the front-line pharmacy staff.

\section{Develop a code of conduct for emergency} pharmacy services

A concise and practical manual that contains easy to follow instructions on how to handle an emergency like COVID-19 is needed. Employees of the pharmacy need to be familiar with the manual. The manual needs to be printed and placed in a prominent position in the workplace to aid employees in knowing their roles and responsibilities. Regularly disinfecting pharmacy areas to guarantee that the pharmacy is safe for people to work and visit. A COVID-19 emergency training program provided by the hospital can educate the pharmacy team on how to protect themselves during patient interactions and be better prepared for COVID-19 through emergency preparedness drills. Emphasize hand sanitization and social distancing as strategies for infection control and provide accurate information to patients and communities on mask selection and use. A pharmaceutical clinic and online pharmaceutical services were offered for medication counseling, chronic disease self-management, providing reliable and evidence-based information during the pandemic. Telepharmacy is important for patients in rural areas and to avoid direct contact, reducing risks of contagion. The COVID-19 pandemic increased focus and emphasis on mental health among patients ${ }^{23}$, 
thus the medical staff needs to take care of people who have been confirmed with or are suspected of having COVID-19, pregnant women might particularly worry about transmitting the virus to the fetus, although whether mother-to-infant transmission is possible remains controversial ${ }^{11,24}$, any suspected COVID-19 infection during pregnancy needs a systematic screening.

\section{CONCLUSIONS}

On the basis of the allocation of pharmaceutical resources in maternal and child healthcare institutions, we saw no scarcity of medical resources or medication errors in our hospital during the COVID-19 pandemic. Our experience could serve as a reference for other hospitals focusing primarily on women and children. It is noteworthy that every country's situation and medical resources are varied, the experience shared here needs to be tailored according to differences in health-care settings and the policies of specific governments.

\section{Acknowledgments \\ Not applicable.}

\section{Author's Contribution}

Cai JH and Chen WW contributed to the work equally and should be regarded as co-first authors. $\mathrm{Li}$ $\mathrm{G}$ had the idea for the article. Yang X and Yang XQ had roles in the literature search. All authors reviewed and approved the final version.

\author{
Funding \\ Not applicable. \\ Declaration of interests \\ All authors declare no competing interests.
}

\section{RESUMO}

Desde o aparecimento de um aglomerado de doentes com pneumonia de causa desconhecida em Wuhan, província de Hubei, China, em dezembro de 2019, a doença foi mais tarde oficialmente nomeada doença do coronavírus 2019 (Covid-19), causada pelo novo vírus da síndrome respiratória aguda grave coronavírus (Sars-CoV-2), que rapidamente se espalhou em nível mundial. As mulheres grávidas e as crianças são particularmente vulneráveis durante catástrofes e emergâncias. A preparação e a resposta de emergência abrangentes e aplicáveis são métodos definitivamente importantes para prevenir e conter a pandemia de Covid-19. A alocação racional dos recursos farmacêuticos desempenha um papel importante no plano de emergência médica. Este documento objetivou compartilhar experiências para a alocação de recursos farmacêuticos em hospitais focando principalmente mulheres e crianças durante a pandemia de Covid-19.

PALAVRAS-CHAVE: Infecções por coronavírus. Gravidez. Criança. Assistência farmacêutica.

\section{REFERENCES}

1. Zhu N, Zhang D, Wang W, Li X, Yang B, Song J, et al; China Novel Coronavirus Investigating and Research Team. A novel coronavirus from patients with pneumonia in China, 2019. N Engl J Med. 2020;382(8):727-33.

2. World Health Organization. Coronavirus disease 2019 (COVID-19). Situation Report - 125. Geneva: World Health Organization; 2020. [cited 2020 May 24]. Available from: https://www.who.int/docs/default-source/coronaviruse/ situation-reports/20200524-COVID-19-sitrep-125.pdf?sfvrsn=80e7d7f0_2

3. Liu H, Wang LL, Zhao S), Kwak-Kim J, Mor G, Liao AH. Why are pregnant women susceptible to COVID-19? An immunological viewpoint. J Reprod Immunol. 2020;139:103122

4. Dong L, Tian J, He S, Zhu C, Wang J, Liu C, et al. Possible vertical transmission of SARS-CoV-2 from an infected mother to her newborn. JAMA 2020;323(18):1846-8.

5. Wu Z, McGoogan IM. Characteristics of and important lessons from the coronavirus disease 2019 (COVID-19) outbreak in China: summary of a report of 72314 cases from the Chinese Center for Disease Control and Prevention. JAMA. 2020. doi: 10.1001/jama.2020.2648.

6. Dong Y, Mo X, Hu Y, Qi X, liang F, liang Z, et al. Epidemiology of COVID-19 among children in China. Pediatrics. 2020;145(6):e20200702.

7. Alfaraj SH, Al-Tawfig|A, Memish ZA. Middle East Respiratory Syndrome Coronavirus (MERS-CoV) infection during pregnancy: report of two cases \& review of the literature. | Microbiol Immunol Infect. 2019;52(3):501-3.
8. Wong SF, Chow KM, Leung TN, Ng WF, Ng TK, Shek CC, et al. Pregnancy and perinatal outcomes of women with severe acute respiratory syndrome. Am | Obstet Gynecol. 2004;191(1):292-7.

9. Favre G, Pomar L, Musso D, Baud D. 2019-nCoV epidemic: what about pregnancies? Lancet. 2020;395(10224):e40.

10. Sutton D, Fuchs K, D'Alton M, Goffman D. Universal screening for SARSCoV-2 in women admitted for delivery. N Engl | Med. 2020;382(22):2163-4.

11. Chen $\mathrm{H}$, Guo J, Wang $\mathrm{C}$, Luo F, Yu X, Zhang W, et al. Clinical characteristics and intrauterine vertical transmission potential of COVID-19 infection in nine pregnant women: a retrospective review of medical records. Lancet. 2020;395(10226):809-15.

12. Bhavsar TR, Kim HJ, Yu Y. Roles and contributions of pharmacists in regulatory affairs at the Centers for Disease Control and Prevention for public health emergency preparedness and response. I Am Pharm Assoc (2003). 2010;50(2):165-8

13. Murphy |K. After 9/11: priority focus areas for bioterrorism preparedness in hospitals. J Healthc Manag. 2004;49(4):227-35.

14. Awad NI, Cocchio C. Assessment of hospital pharmacy preparedness for mass casualty events. P T. 2015;40(4):264-7.

15. Emanuel EJ, Persad G, Upshur R, Thome B, Parker M, Glickman A, et al. Fair allocation of scarce medical resources in the time of COVID-19. N Engl | Med. 2020;382(21):2049-55. 
16. Prouillac C, Lecoeur $S$. The role of the placenta in fetal exposure to xenobiotics: importance of membrane transporters and human models for transfer studies. Drug Metab Dispos. 2010;38(10):1623-35.

17. National Health Commission of the People's Republic of China. Diagnosis and treatment guidelines for the new coronavirus infected pneumonia. [cited 2020 Mar 4]. Available from: http://www.nhc.gov.cn/yzygj/s7653p/202003/ 46c9294a7dfe4cef80dc7f5912eb1989.shtml

18. Ruan Q, Yang K, Wang W, Jiang L, Song J. Clinical predictors of mortality due to COVID-19 based on an analysis of data of 150 patients from Wuhan, China. Intensive Care Med. 2020;46(5):846-8.

19. Lu X, Zhang L, Du H, Zhang J, Li YY, Qu J, et al; Chinese Pediatric Novel Coronavirus Study Team. SARS-CoV-2 infection in children. N Engl J Med. 2020;382(17):1663-5.

20. Aruru M, Truong HA, Clark S. Pharmacy Emergency Preparedness and Response (PEPR): a proposed framework for expanding pharmacy professionals' roles and contributions to emergency preparedness and response during the COVID-19 pandemic and beyond. Res Social Adm Pharm. 2020;S1551-7411(20)30323-5.

21. Liu S, Luo P, Tang M, Hu Q, Polidoro JP, Sun S, et al. Providing pharmacy services during the coronavirus pandemic. Int J Clin Pharm. 2020;42(2):299-304.

22. South China Morning Post. Chinese hospital pharmacist, 28, dies after 10 straight days helping fight coronavirus. [cited 2020 Apr 2]. Available from: https://www.scmp.com/news/china/society/article/3049381/ chinesehospital-pharmacist-28-dies-after-10-straight-days

23. Xiang YT, Yang Y, Li W, Zhang L, Zhang Q, Cheung T, et al. Timely mental health care for the 2019 novel coronavirus outbreak is urgently needed. Lancet Psychiatry. 2020;7(3):228-9.

24. Zhu H, Wang L, Fang C, Peng S, Zhang L, Chang G, et al. Clinical analysis of 10 neonates born to mothers with 2019-nCoV pneumonia. Transl Pediatr. 2020;9(1):51-60. 